\title{
Direct rate assessment of laccase catalysed radical formation in lignin by electron paramagnetic resonance spectroscopy
}

Munk, Line; Andersen, Mogens Larsen; Meyer, Anne S.

Published in:

Enzyme and Microbial Technology

Link to article, DOI:

10.1016/j.enzmictec.2017.07.006

Publication date:

2017

Document Version

Peer reviewed version

Link back to DTU Orbit

Citation (APA):

Munk, L., Andersen, M. L., \& Meyer, A. S. (2017). Direct rate assessment of laccase catalysed radical formation in lignin by electron paramagnetic resonance spectroscopy. Enzyme and Microbial Technology, 106, 88-96. https://doi.org/10.1016/j.enzmictec.2017.07.006

\section{General rights}

Copyright and moral rights for the publications made accessible in the public portal are retained by the authors and/or other copyright owners and it is a condition of accessing publications that users recognise and abide by the legal requirements associated with these rights.

- Users may download and print one copy of any publication from the public portal for the purpose of private study or research.

- You may not further distribute the material or use it for any profit-making activity or commercial gain

- You may freely distribute the URL identifying the publication in the public portal 


\section{Accepted Manuscript}

Title: Direct rate assessment of laccase catalysed radical formation in lignin by electron paramagnetic resonance spectroscopy

Authors: Line Munk, Mogens Larsen Andersen, Anne S. Meyer

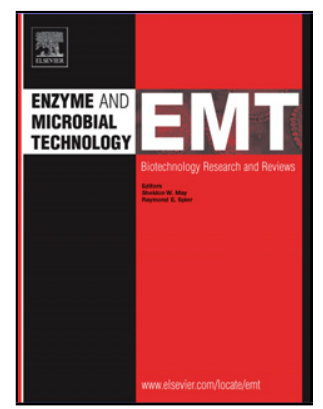

PII: S0141-0229(17)30133-3

DOI:

Reference: http://dx.doi.org/doi:10.1016/j.enzmictec.2017.07.006

To appear in: $\quad$ Enzyme and Microbial Technology

Received date: $\quad 1-5-2017$

Revised date: $\quad 12-7-2017$

Accepted date: $\quad$ 13-7-2017

Please cite this article as: Munk Line, Andersen Mogens Larsen, Meyer Anne S.Direct rate assessment of laccase catalysed radical formation in lignin by electron paramagnetic resonance spectroscopy.Enzyme and Microbial Technology http://dx.doi.org/10.1016/j.enzmictec.2017.07.006

This is a PDF file of an unedited manuscript that has been accepted for publication. As a service to our customers we are providing this early version of the manuscript. The manuscript will undergo copyediting, typesetting, and review of the resulting proof before it is published in its final form. Please note that during the production process errors may be discovered which could affect the content, and all legal disclaimers that apply to the journal pertain. 


\section{Direct rate assessment of laccase catalysed radical formation in lignin by electron}

\section{paramagnetic resonance spectroscopy}

Line Munk ${ }^{\mathrm{a}}$, Mogens Larsen Andersen ${ }^{\mathrm{b}}$, Anne S. Meyer ${ }^{\mathrm{a},{ }^{*}}$

${ }^{a}$ Center for Bioprocess Engineering, Department of Chemical and Biochemical Engineering, Building 229,

Technical University of Denmark, 2800 Kgs. Lyngby,Denmark

b University of Copenhagen, Faculty of Science, Department of Food Science, Rolighedsvej 30, 1958 Frederiksberg C, Denmark

${ }^{*}$ Corresponding author. Address as above, E-mail: am@kt.dtu.dk (Anne S. Meyer)

Highlights

- Time course EPR measurement of direct radical formation by fungal laccases on genuine lignin samples

- Assessment of enzyme kinetic rates of radical formation in lignin by two fungal laccases

- Identification of different radical formation patterns by a low and high redox potential laccase

- Demonstration of different laccase rates on different types of lignin substrates

\section{Abstract}

Laccases (EC 1.10.3.2) catalyse removal of an electron and a proton from phenolic hydroxyl groups, including phenolic hydroxyls in lignins, to form phenoxy radicals during reduction of $\mathrm{O}_{2}$. We employed electron paramagnetic resonance spectroscopy (EPR) for real time measurement of such catalytic radical 
formation activity on three types of lignin (two types of organosolv lignin, and a lignin rich residue from wheat straw hydrolysis) brought about by two different fungal laccases, derived from Trametes versicolor (Tv) and Myceliophthora thermophila (Mt), respectively. Laccase addition to suspensions of the individual lignin samples produced immediate time and enzyme dose dependent increases in intensity in the EPR signal with g-values in the range 2.0047-2.0050 allowing a direct quantitative monitoring of the radical formation and thus allowed laccase enzyme kinetics assessment on lignin. The experimental data verified that the laccases acted upon the insoluble lignin substrates in the suspensions. When the action on the lignin substrates of the two laccases were compared on equal enzyme dosage levels (by activity units on syringaldazine) the Mt laccase exerted a significantly faster radical formation than the Tv laccase on all three types of lignin substrates. When comparing the equal laccase dose rates on the three lignin substrates the enzymatic radical formation rate on the wheat straw lignin residue was consistently higher than that of the organosolv lignins. The $\mathrm{pH}$-temperature optimum for the radical formation rate in organosolv lignin was determined by response surface methodology to $\mathrm{pH} 4.8,33^{\circ} \mathrm{C}$ and $\mathrm{pH} 5.8,33^{\circ} \mathrm{C}$ for the Tv laccase and the Mt laccase, respectively. The results verify direct radical formation action of fungal laccases on lignin without addition of mediators and the EPR methodology provides a new type of enzyme assay of laccases on lignin.

\section{Keywords}

Laccase kinetics, Real time assay, phenoxy radicals in lignin, EPR, dose-response treatment

\section{Introduction}

Lignin is a heterophenolic biopolymer present in the plant cell walls of terrestrial plants. In the plants, lignin is synthesized via coupling reactions between primarily three phenylpropanoid subunits, $p$-coumaryl 
alcohol (H-unit), coniferyl (guaiacyl) alcohol (G-unit), and syringyl alcohol (S-unit), to form a hydrophobic, insoluble network linked together by ether and carbon-carbon bonds [1,2]. The lignin network essentially surrounds the plant polysaccharides in each plant cell wall and typically constitutes $10-30 \%$ of lignocellulosic plant material [1]. It is considered useless for biomass processing and in current biorefineries residual lignin is combusted for internal energy consumption. However, it has been estimated that a surplus of lignin of $\sim 60 \%$ beyond what is needed for process energy is present in today's cellulosic ethanol biorefineries [2]. Hence, a significant potential exists for exploitation of lignin to create value added products without compromising internal process requirements of biorefineries, and development of e.g. aromatic derived chemicals or functionalized polymeric materials by various catalytic technologies has already been reported in the literature [2-6].

Oxidoreductases expressed by certain white-rot and soft-rot fungi and even some bacteria catalyse lignin modification in nature as part of the global carbon biodegradation cycle [7-9]. Among these enzymes laccases (benzenediol:oxygen oxidoreductase, EC 1.10.3.2) uses molecular oxygen to catalyse oxidation of phenolic substrates similar to those found in lignin subunits. A laccase catalysed oxidation cycle involves oxidation of four moles of phenolic substrate and simultaneous reduction of one mole of $\mathrm{O}_{2}$ to $\mathrm{H}_{2} \mathrm{O}[10,11]$. Because of the direct utilization of $\mathrm{O}_{2}$, as opposed to requiring $\mathrm{H}_{2} \mathrm{O}_{2}$, laccases are particularly interesting for practical use in biocatalytic lignin modification. Laccase catalysed action on lignin leads to phenoxy radicals which in turn induce a variety of non-enzymatic reactions including radical polymerization, bond cleavage, grafting, and modification of functional groups - all reactions which may be harnessed to functionalize lignin [12-15]. Elegant screening assays for enzymatic lignin oxidation have been reported [16,17], but unfortunately, these assays as well as detailed kinetic studies of laccases employ soluble phenols (monomeric and dimeric lignin model compounds) or are based on substrates such as ABTS (2,2'-azinobis(3-ethylbenzothiazoline-6-sulphonic acid) or syringaldazine (4-hydroxy-3,5-dimethoxy-benzaldehyde azine) which relate poorly to lignin with respect to molecular weight, solubility, and chemical composition. 
The objective of this study was to examine if it is possible to assess laccase reactivity and kinetics on lignin directly by measuring the enzyme catalysed radical formation on lignin by electron paramagnetic resonance (EPR) spectroscopy. A second purpose was to quantitatively compare the activities of two different fungal laccases directly on three types of lignin to assess any differences or similarities in kinetic rates; the three lignin substrates employed included two pure (organosolv) lignins and a lignin-rich residue from wheat straw obtained after extensive cellulase treatment. The laccases examined included a low redox potential ( $\sim 0.5 \mathrm{~V}$ vs NHE) laccase derived from the soft rot ascomycete Myceliophthora thermophila and a high redox potential ( $0.7 \vee$ vs NHE) laccase originating from the white rot basidiomycete Trametes versicolor [18-20].

\section{Materials and Methods}

\subsection{Lignins}

Two organosolv lignins were employed: an organosolv lignin (CAS No. 8068-03-9) obtained from SigmaAldrich (Milwaukee, WI, USA) (SOL) and a beech organosolv lignin (BOL) produced at Thünen Institute of Wood Research (Hamburg, Germany) [21]. These organosolv lignins were dry powders with a volume-based particle size of $\mathrm{D}[4,3]=11.2 \mu \mathrm{m}$ for SOL and $\mathrm{D}[4,3]=6.4 \mu \mathrm{m}$ for BOL. Both SOL and BOL represented substrates with high lignin content comprising 94 wt\% and 87.4 wt\% of Klason lignin, respectively.

Wheat straw lignin (WSL) was a hydrothermally pretreated wheat straw sample that had been exhaustively enzymatically treated with a Cellic CTec2 enzyme cocktail from Novozymes (Bagsværd, Denmark). The wheat straw had first been hydrothermally pre-treated in a pilot plant facility $\left(10 \mathrm{~min}, 190^{\circ} \mathrm{C}\right)$ according to [22]. After pre-treatment, the insoluble fiber fraction was suspended to $4.5 \mathrm{wt} \%$ dry matter (DM) and treated for $48 \mathrm{~h}$ with a Cellic $\mathrm{CTec} 2$ at $\mathrm{pH} 5.1,50{ }^{\circ} \mathrm{C}$. The Cellic $\mathrm{CTec} 2$ enzyme preparation was added in a ratio of $0.5 \%$ by weight (liquid) to wheat straw (DM) and 0.02 wt\% sodium azide was added as preservative. After the first enzymatic treatment, the suspension was centrifuged for $20 \mathrm{~min}$ at $5350 \mathrm{~g}$ and the pellet obtained washed twice with deionized water; this procedure was repeated twice. The final wheat 
straw lignin pellet resulting after three rounds of enzymatic treatment was washed, dried at $70{ }^{\circ} \mathrm{C}$, ground and sieved to obtain a resulting volume-based particle size of $D[4,3]=15.8 \mu \mathrm{m}$. This wheat straw lignin (WSL) sample contained 43.7 wt\% of Klason lignin (and 37.8 wt\%cellulose, $9.2 w t \%$ hemicellulose, and $6.1 \mathrm{wt} \%$ ash).

\subsection{Compositional analyses and particle size}

Compositional analyses of the three lignin biomasses were conducted according to the NREL Standard Procedure for Biomass Compositional Analysis [23]. The particle size distributions of the different (milled) lignin samples were determined using a Malvern Mastersizer 2000 (Malvern, UK).

\subsection{Laccases}

The fungal laccase derived from Trametes versicolor (Tv) was obtained from Fluka (St. Gallen, Switzerland) and the Myceliophthora thermophila (Mt) laccase was a gift from Novozymes (Bagsværd, Denmark).

\subsection{Laccase activity assay}

Laccase activity was determined by monitoring the oxidation of syringaldazine at $530 \mathrm{~nm}\left(\varepsilon=6.5 \cdot 10^{4} \mathrm{M}^{-1}\right.$ $\mathrm{cm}^{-1}$ ) during reaction at $25{ }^{\circ} \mathrm{C}$. The assay reaction mixture contained $0.25 \mathrm{mM}$ syringaldazine, 10 vol\% methanol, $25 \mathrm{mM}$ sodium acetate $(\mathrm{pH} 5.0)$ and a suitable amount of enzyme. Enzyme activity was expressed in units: One International Unit (U) was defined as the amount of enzyme required to catalyse conversion of $1 \mu \mathrm{mol}$ of substrate (syringaldazine) per minute under the assay reaction conditions.

\subsection{Dose-response study of radical formation catalyzed by laccases}

Each of the lignin samples were suspended in Milli-Q water resulting in a $10 \mathrm{wt} \%$ lignin suspension. After 30 min. the suspensions were adjusted to $\mathrm{pH} 5$ by ammonia and acetic acid. The laccase treatments were conducted as stochastically independent timed reactions (i.e. individual, timed reactions were carried out for each time point) in aliquots of $250 \mu \mathrm{l}$ carried out in darkness at $25^{\circ} \mathrm{C}$. To avoid that oxygen would be the rate-limiting factor samples were vigorously shaken at $1400 \mathrm{rpm}$ and sealed with gas permeable, water 
proof membranes (ABgene, Surrey, UK) to optimise oxygen saturation. Laccases were dosed in $0.5,1.0$ or $2.0 \mathrm{U} / \mathrm{g}$ of solid (DM) (Units according to the syringaldazine assay) and $50 \mu$ l of suspension or supernatant (after $45 \mathrm{sec}$ of centrifugation) was sampled to mediate EPR measurements in a time span of 0-35 min. Reference treatments for each time point were carried out at similar conditions, but without any laccase addition.

\subsection{Optimization study by response surface modeling}

A 3-level full factorial design with the highest laccases dose $(2 \mathrm{U} / \mathrm{g})$ was carried out to study the influence of $\mathrm{pH}$ and temperature on the rate of laccase catalysed radical formation in the organosolv lignin from Sigma (SOL). Each variable ( $\mathrm{pH}$ and temperature) was considered at three levels including a center point (in triplicates), which represented the midpoint of each factor range. Based on preliminary experiments, the actual levels were set to $\mathrm{pH} 4-6$ and $25-50^{\circ} \mathrm{C}(\mathrm{pH} 5,37.5$ as center point) giving a total of 12 experiments for each of the two laccases. The lignin substrate concentration was $10 \%$ by weight in all experiments. The response values were given as the rate of radical formation $(\mu \mathrm{M} / \mathrm{min})$, which were based on initial rate determination from time curves (0-25 min.) with a minimum of 6 data points (data not shown). The statistical design program MODDE 12.01 (Umetri AB, Umeå, Sweden) was used as an aid to statistically design the factorial experiments and to fit and analyse the data by multiple linear regression. Significance of the results was established at $P \leq 0.05$.

\subsection{Electron paramagnetic resonance spectroscopy (EPR)}

The laccase catalysed radical formation in the lignin suspensions and their corresponding supernatant(s) were determined directly by Electron Paramagnetic Resonance (EPR) spectroscopy. At selected time points from 0-35 min. a sample from a timed reaction was drawn into a $50 \mu$ l capillary tube during vigorous shaking, and care was taken to ensure that the EPR measurement was always done at the same time immediately after the sample had been drawn into the capillary tube to avoid any possible measurement variation caused by sedimentation in the tube and securing that the sensitive part of the capillary tube was 
free of air bubbles. EPR detection was carried out immediately after sampling at $20{ }^{\circ} \mathrm{C}$ with a MiniScope MS200 (Magnettech, Berlin, Germany) using the following settings: Modulation amplitude of $0.2 \mathrm{mT}$; center field $336.7 \mathrm{mT}$, sweep width $10 \mathrm{mT}$, and a sweep time of $30 \mathrm{sec}$. The number of spins was calculated by double integration of the resonance signal lines after background subtraction (i.e. subtraction of the resonance signal line of the reference treatment). The area under the absorption signal was converted to a radical concentration through a linear standard curve $\left(R^{2}=0.99\right)$ based on solutions of $0.5-100 \mu \mathrm{M}$ the stable nitroxyl radical TEMPO (g-value of TEMPO 2.0060) (Sigma-Aldrich, Milwaukee, WI, USA).

\subsection{Determination of $g$-values by EPR}

The types of radicals generated by laccase catalysis in individual suspensions of the three lignins were determined by resolving the g-values of the EPR signals. The g-values of the lignin suspensions and their corresponding supernatants were based on EPR measurements using samples dosed with 2 laccase U/g solid lignin after 16-30 minutes of incubation where the radical response were strongest. The g-values were calculated by determining the field strength where the spectrum, presented as the first derivative of the absorption signal, passed through zero.

\section{Results and discussion}

\subsection{Laccase catalysed activation of lignin suspensions}

The EPR analyses of the lignin suspensions with laccase added showed an immediate time dependent increase in the isotropic signal intensity in all suspensions as a result of laccase treatment (Fig. 1). All samples provided EPR spectra with a single broad signal, which corresponded well with EPR spectral data reported for similar substrates $[24,25]$. The spectra (Fig 1.) showed no pronounced resolved hyperfine interactions and were slightly asymmetric indicating anisotropic signals as previously reported for lignin derived phenoxyl radicals [24] or that more than one type of radical was formed [26]. 
The g-values derived from the EPR spectra of the lignin suspensions after laccase treatment were close to 2.005 (Table 1) with beech organosolv lignin (BOL) producing the highest g-value of 2.0051 and Sigma organosolv lignin (SOL) and wheat straw lignin (WSL) generating g-values of 2.0046 and 2.0047, respectively (Table 1). These values were in agreement with those reported for lignin derived phenoxy radicals in the literature of $g=2.004[3,25,27]$. As the presence of different radicals affect the $g$ factor of the EPR spectra, the slightly higher values recorded may be explained by the presence or predominance of other stable radicals such as e.g. semi-quinones known to be present in organosolv lignin $[24,28]$.

There were no evident shifts in the g-values during the time span of any of the reactions, suggesting that the type of generated radicals remained the same throughout the laccase catalysed reaction in the three different lignin suspensions. Likewise, the similarity in the g-values of the EPR signal generated by the Trametes versicolor (Tv) laccase and the Myceliophthora thermophila (Mt) laccase, suggests that the two laccases catalysed the formation of the same type of radicals in the lignins.

\subsection{Distribution of radicals in lignin suspensions}

In order to assure that the radical responses were not exclusively caused by soluble phenolics in the suspensions, the supernatants of the suspensions treated with the highest dose of laccase $(2 \mathrm{U} / \mathrm{g})$ were analysed separately by EPR spectrometry. An evident difference in signal intensity between the suspension and the corresponding supernatant were demonstrated for all three lignins, i.e. the signal intensities of the supernatants were small, and evidently significantly lower than those of the suspensions, and notably the supernatants of the SOL and the WSL samples did not elicit any significant responses to laccase treatment (fig 2a). This distinct difference in intensity between the whole suspension and the corresponding supernatant emphasized that laccase indeed facilitated formation of radicals in the solid insoluble part of lignin. (Small, but constant EPR signals were detected in the EPR spectra of substrates without laccase. It is assumed that these signals may have occurred as a result of spontaneous oxidation of phenolic groups in 
lignin during the lignin storage prior to experimentation. These spectra were subtracted from the spectra of laccase treated samples before quantification into radical concentrations).

The evolution of phenoxy radical formation in the supernatants differed among the substrates, but not between the two laccases (fig $2 \mathrm{~b}$-d). Among the three substrates, laccase treatment of BOL appeared to generate the highest concentration of radicals in the supernatant constituting $20-30 \%$ of the radicals in suspension throughout the time of measurement, and the formation of radicals moreover increased throughout the reaction at a constant rate $(0.3 \mu \mathrm{M} / \mathrm{min})(\mathrm{fig} 2 \mathrm{~b})$. In the SOL sample, however, the concentration of phenoxy radicals in the supernatants initially increased but then declined after 10-20 min and after $25 \mathrm{~min}$ the level was practically negligible $(<2-2.5 \mu \mathrm{M})$ (fig $2 \mathrm{c})$. Upon laccase treatment, the WSL samples had the lowest contribution of radicals in the supernatants relative to the radical concentration in the suspensions. This low contribution was presumably related to the fact that the WSL substrate had been extensively washed prior to being used in the reactions. The concentration of phenoxy radicals in the supernatants thus constituted less than $10 \%$ of the radicals in the suspension during most of the time of measurement (fig $2 \mathrm{~d}$ ). In general, the EPR spectra of the radicals from the supernatants produced higher gvalues compared to radicals from the corresponding suspensions, but it was most pronounced for the SOL samples (Table 1). The difference in g-values between radicals in the supernatants and the suspensions may suggest that the distribution of phenoxy radical species was slightly different in the supernatants and in the suspensions of the lignin samples [24].

\subsection{Steady state concentration of radicals in lignin suspensions}

In the progress curves depicting the evolution of radicals formation in the lignin samples treated with the highest dose of laccase, the EPR measurements were prolonged until a steady state was reached and an overall decay of the accumulated radicals occurred (Fig. 3). Such decay of radicals is known to occur simultaneously with the formation of radicals. When the overall concentration of radicals starts to decline, the rate of generated radicals is surpassed by the radical decay rate. The radical decay is most likely due to 
radical-radical reactions leading to non-radical products in the lignin or grafting of low-weight molecules onto the lignin polymer [29].

The highest concentration of phenoxy radicals in the suspensions was achieved with laccase treatment of $\mathrm{BOL}$ with the highest dose (2U/g solid) and the level of radicals reached almost $45 \mu \mathrm{M}$ with the Tv laccase and $60 \mu \mathrm{M}$ with the Mt laccase after $35 \mathrm{~min}$ (Fig. 3a,d). After 1 hour, the radical concentration of these particular reactions reached $78 \mu \mathrm{M}$ and $65 \mu \mathrm{M}$ with the Tv laccase and Mt laccase, respectively (data not shown). The finding that the highest radical concentration was reached by the Tv laccase despite a slower rate may be explained by the higher redox potential of Tv laccase enhancing the oxidising capacity to more phenols then the Mt laccase that is classified as a low redox potential laccase. The highest radical concentrations in the laccase treatments of SOL and WSL were remarkably lower reaching 36-45 $\mu \mathrm{M}$ after 20-25 min (Fig. 2b-c, 2e-f).

Low-molecular weight aromatic compounds have been demonstrated to function as mediators in laccase oxidation systems [30,31]. It could therefore be speculated that the remarkably higher radical concentration achieved in the suspensions of $\mathrm{BOL}$ could be due to a higher concentration of small, soluble radical compounds in the supernatant of BOL as compared to those in the SOL and WSL supernatants (Fig 2); if so, these radicals in the BOL supernatant could function as mediators, and thus increase the oxidation capability of laccase towards BOL.

\subsection{Real time assay of laccase action on lignin by EPR}

When the EPR signals, whether given as intensity or quantified to $\mu \mathrm{M}$ of radicals, were expressed as a function of time, the laccase treated lignin suspensions showed a clear dose dependent increase in the accumulated number of radicals (Fig. 3). For each substrate and for each laccase dose, the initial time interval where the radical concentration increased linearly provided the basis for determination of initial rates. A linear dose-dependence between laccase dose and the initial radical response rate was evident in all three substrates when plotting the initial rates from each substrate as a function of laccase dose for TV 
laccase and Mt laccase (Fig. 4). The calculated slopes of the dose-response reactions all correlated linearly $\left(R^{2} \geq 0.997\right)$. For both laccases, the dose-response treatments affected the initial rate of the radical response in the lignins in following order; WSL $\geq S O L \geq B O L$. Surprisingly, this order also correlated with the particle size (WSL $\geq S O L \geq B O L)$. The rate response to particle size was expected to be inversely correlated, since substrates with small particle size generally means a larger surface area available for enzymes to access, and hence are more likely to be affected by increasing enzyme dosage. This lack of a clear inverse correlation to substrate particle size suggests that other factors besides the particle size, e.g. distribution of subunits and phenolic groups in lignins influenced the rate of radical formation which is actually in accordance with what has been reported earlier [27]. The increase in initial rate as response to the increase in Mt laccase dose was specifically high for WSL substrate, but when accounting for the lignin content in BOL, SOL and WSL, the dose-response effect on the WSL and BOL substrates were similar for both laccases, while the dose-response effect was significantly higher on the SOL substrate (table 2, column 4 and 5).

Although the laccases were dosed according to activity units of the assay substrate (syringaldazine), increasing dose of the Mt laccase with low oxidation potential appeared to induce a significantly stronger initial response in all three lignins compared Tv laccase with high oxidation potential (Table 2). This set of results indicates that the redox potential of laccases may have more impact on the total amount of lignin subunits that can be oxidized by laccase rather than on the initial rate of the oxidation. Such information which is important for lignin upgrading cannot be obtained from conventional laccase assays and emphasizes the necessity for assessing laccase activity on genuine lignin samples.

\subsection{Temperature and pH optimization of laccase catalysed radical formation in lignin}

A 3-level full factorial design was designed for both Tv and Mt laccase to assess if a pH-temperature optimum for each enzyme on genuine lignin could be established by measuring radical formation by EPR.From the data obtained a second-order polynomial equation for the radical formation rate was identified for each laccase by multiple linear regression: 
Tv laccase: $Y=0.925-0.19667 X_{2}-0.2525 X_{1}^{2}-0.3175 X_{2}^{2}$

Mt laccase: $Y=1.73208+0.059 X_{1}-0.28167 X_{2}-0.40125 X_{1}^{2}-0.60625 X_{2}^{2}$

$Y$ is the radical formation rate $(\mu \mathrm{M} / \mathrm{min}), X_{1}$ is $\mathrm{pH}$ and $X_{2}$ is the temperature $\left({ }^{\circ} \mathrm{C}\right)$. Since $\mathrm{pH}$ within the range tested was not significant for the Tv laccase catalysis (discussed below) this main factor was removed from the model for Tv laccase above, analogously the non-significant interaction between $\mathrm{pH}$ and temperature ( $\mathrm{pH}^{*}$ Temp), also to be discussed below, has been removed from both models (Supplementary data Table S1 and S2). Both models expressed a good model fit with high significance $\left(R^{2} \geq 0.93\right)$ and acceptable predictive squared correlation coefficients $\left(Q^{2} \geq 0.44\right)$ (Supplementary data Figure S1 and S2); the low model validity is a result of the design, i.e. the regression model being based on only 2 variables ( $\mathrm{pH}$ and temperature). Any possible solubilisation of lignin with increasing $\mathrm{pH}$ was not evident as no differences in the EPR signals of the lignin suspensions without laccase were apparent within the pH-range studied. Not all regression coefficients were statistically significant $(P \leq 0.05)$ (Supplementary data Table S1 and S2). The $\mathrm{pH}^{*}$ Temp interaction regression coefficients were not significant for any of the enzymes, meaning that in the $\mathrm{pH}$ and temperature interval studied the laccase catalysed radical formation in SOL was not influenced differently by $\mathrm{pH}$ when the temperature was changed and vice versa. Based on the model equations predicted responses could be graphically depicted as contour and response surface plots (Fig. 5 and 6). The plots visualise the optimal conditions (within the limits of the experiment) for the radical formation and illustrate the influence of the variables $(\mathrm{pH}$ and temperature) on the rate of radical formation induced by the Tv laccase (Fig. 5) and the Mt laccase (Fig. 6). The temperature, but not the pH, significantly affected the radical formation for the Tv laccase (Supplementary data Table S1); nevertheless the optimal conditions for radical formation in SOL catalysed by Tv laccase was predicted to be $\mathrm{pH} 4.8$ at $33^{\circ} \mathrm{C}$ (Figure 5). For the Mt laccase the radical formation was affected by the temperature as well as by the $\mathrm{pH}$ and the optimal reaction condition for $\mathrm{Mt}$ laccase was predicted to be 5.8 at $33^{\circ} \mathrm{C}$ (Figure 6). Although $\mathrm{pH}$ optima of laccases may depend on the substrate used, laccases from white rot fungi typically have $\mathrm{pH}$ optima in the range of 
$\mathrm{pH} 3-5$, which corresponds well with the result for Tv laccase [19]. The higher $\mathrm{pH}$ of the Mt laccase is also in accordance with result previously determined on phenolic substrates [20]. The temperature optimum of $33^{\circ} \mathrm{C}$ for both laccases is lower than what is commonly reported for both enzymes $\left(50{ }^{\circ} \mathrm{C}\right)[18-20]$, but could be due to the initial rate in other studies being determined during only a few minutes of reaction on model substrates.

The data obtained show that the stable nature of phenoxy radicals enables real time measurement of laccase catalyzed radical formation in lignin suspensions by EPR analysis $[25,32]$. The EPR methodology lends itself directly to assess enzyme kinetic parameters of laccases acting on lignin e.g. the maximum catalytic conversion rate, $k_{c a t}$, defined as number of substrate molecules converted per second per enzyme, provided that the number of substrate molecules is counted as equivalent to each radical generated. However, measurement of e.g. substrate affinity, $K_{M}$, defined as the substrate concentration at which the enzymatic rate is half of the maximal attainable rate $\left(V_{\max }\right)$, is limited by the current general analytical complexity of structural lignin characterization, including analytical resolution of lignin surface chemistry. Integration of EPR analysis of laccase attack on lignin with advanced lignin analyses, e.g. multidimensional NMR and coherent anti-Stokes Raman scattering analyses combined with molecular dynamics simulations (methods that have been suggested promising for providing improved atomic level understanding of lignin [33]) may provide new insights into lignin reactivity and how laccases function on lignin. For now, the obtained linearity of the relations between initial rates and laccase doses in the present work verifies that EPR monitoring of laccase action on lignin suspensions can be used as a real time assay to determine laccase activity on genuine lignin substrates.

\section{Conclusion}

Previous studies examining radical formation in lignin or fibres during laccase treatment have mainly applied approaches of drying or freezing of sample prior to EPR spectroscopy measurements. The method applied in this study was based upon real time measurement on lignin suspensions during laccase action 
thus providing quantifiable kinetic information about the activation of lignin during laccase treatment without addition of mediators. The initial rate of radical formation as a result of increased laccase dose was significantly higher for Mt laccase, while the TV laccase was superior in generating the highest radical concentration after extended reaction, but at a slower rate. The suggested method was also successfully demonstrated to be applicable for establishing optimal $\mathrm{pH}$ and temperature conditions for laccase catalysed formation of radicals in lignin. A smaller particle size, did not appear to have an impact on the rate of radical formation, as wheat straw lignin residue having the largest particle size also displayed the highest enzymatic radical formation rate. It is still debated how laccases participate in lignin degradation and how they interact with lignin, whether it is by direct interaction with the lignin polymer or by means of small mediators naturally occurring in the substrate or compounds added to the system. The present development of a laccase assay based on lignin as substrate can hopefully help in providing new knowledge that improves the understanding of laccase action on lignin biomass to pave the way for harnessing laccases for development of new lignin upgrading processes.

\section{Acknowledgments}

This study was partially supported by the Danish National Advanced Technology Foundation via the Technology Platform "Biomass for the 21st century - B21st". We thank University of Hamburg, Germany for the donation of a beech organosolv sample and Novozymes (Bagsværd, Denmark) for donating the Myceliophthora thermophila laccase. 


\section{References}

[1] Gellerstedt C, Henriksson G. Lignins: major sources, structure and properties. In: Belgacem M, Gandini A, editors. Monomers, polymers and composites from renewable resources. Amsterdam, The Netherlands: Elsevier 2008. p. 201-24.

[2] Raguaskas AJ, Beckham GT, Biddy MJ, Chandra R, Chen F, Davis MF et al. Lignin valorization: Improving lignin processing in the biorefinery. Science. 2014;344:709-719

[3] Crestini C, Crucianelli M, Orlandi M, Saladino R. Oxidative strategies in lignin chemistry: A new environmental friendly approach for the functionalisation of lignin and lignocellulosic fibers. Catal. Today. 2010;156:8-22.

[4] Gasser CA, Hommes G, Schaffer A, Corvini PF. Multi-catalys reactions: new prospects and challenges of biotechnology to valorize lignin. Appl. Microbiol. Biotechnol., 2012;95:1115-34.

[5] Rinaldi R, Jastrzebski R, Clough MT, Ralph J, Kennema M, Bruijnincx PCA, et al. Paving the Way for Lignin Valorisation: Recent Advances in Bioengineering, Biorefining and Catalysis. Angew. Chem. Int. Ed. 2016;55:8164-215.

[6] Widsten P, Heathcote C, Kandelbauer A, Guebitz G, Nyanhongo GS, Prasetyo EN, et al. Enzymatic surface functionalisation of lignocellulosic materials with tannins for enhancing antibacterial properties. Process Biochem. 2010;45:1072-81.

[7] Daniel G. Fungal and bacterial biodegradation: white rots, brown rots, soft rots, and bacteria. ACS Symp. Ser. 2014;1158:23-58.

[8] Hatakka A. Lignin-modifying enzymes from selected white-rot fungi: production and role in lignin degradation. FEMS Microbiol. Rev. 1994;13:125-35.

[9] Liers C, Arnstadt T, Ullrich R, Hofrichter M. Patterns of lignin degradation and oxidative enzyme secretion by different wood- and litter-colonizing basidiomycetes and ascomycetes grown on beechwood. FEMS Microbiol. Ecol. 2011;78:91-102.

[10] Jones SM, Solomon El. Electron transfer and reaction mechanism of laccases. Cell. Mol. Life Sci. 2015;72:869-83.

[11] Sitarz AK, Mikkelsen JD, Meyer AS. Structure, functionality and tuning up of laccases for lignocellulose and other industrial applications. Crit. Rev. Biotechnol. 2016;36:70-86.

[12] Kudanga T, Nyanhongo GS, Guebitz GM, Burton S. Potential applications of laccase-mediated coupling and grafting reactions: A review. Enzyme Microb. Technol. 2011;48:195-208.

[13] Mai C, Schormann W, Hüttermann A, Kappl R, Hüttermann J. The influence of laccase on the chemoenzymatic synthesis of lignin graft-copolymers. Enzyme Microb. Technol. 2002;30:66-72. 
[14] Munk L, Sitarz AK, Kalyani DC, Mikkelsen JD, Meyer AS. Can laccases catalyze bond cleavage in lignin? Biotechnol. Adv. 2015;33:13-24.

[15] Widsten P, Kandelbauer A. Laccase applications in the forest products industry: A review. Enzyme Microb. Technol. 2008;42:293-307.

[16] Ahmad M, Taylor C, Pink D, Burton K, Eastwood D, Bending GD, Bugg TD. Development of novel assays for lignin degradation: comparative analysis ofbacterial and fungal lignin degraders, Mol. Biosyst. 2010;6: 815-821.

[17] Tonin F, Vignali E, Pollegioni L, D’Arrigo P, Rosini E. A novel, simple screening method for investigating the properties of lignin oxidative activity. Enzyme Microb. Technol. 2017;96:143-150.

[18] Berka RM, Schneider P, Golightly EJ, Brown SH, Madden M, Brown KM, et al. Characterization of the gene encoding an extracellular laccase of Myceliophthora thermophila and analysis of the recombinant enzyme expressed in Aspergillus oryzae. Appl. Environ. Microbiol. 1997;63:3151-7.

[19] Han M, Choi $H$, Song $H$. Purification and characterization of laccase from the white rot fungus Trametes versicolor. J. Microbiol. (Seoul). 2005;43:555-60.

[20] Xu F, Berka RM, Wahleithner JA, Nelson BA, Shuster JR, Brown SH, et al. Site-directed mutations in fungal laccase: effect on redox potential, activity and pH profile. Biochem. J. 1998;334:63-70.

[21] Podschun J, Saake B, Lehnen R. Reactivity enhancement of organosolv lignin by phenolation for improved bio-based thermosets. Eur. Polym. J. 2015;67:1-11.

[22] Ambye-Jensen M, Thomsen ST, Kádár Z, Meyer AS. Ensiling of wheat straw decreases the required temperature in hydrothermal pretreatment. Biotechnol. Biofuels. 2013;6:116.

[23] Sluiter A, Hames B, Ruiz R, Scarlata C, Sluiter J, Templeton D, et al. Determination of structural carbohydrates and lignin in biomass. Laboratory Analytical Procedure. NREL/TP-510-42618 (Version 07.08.2011). National Renewable Energy Laboratory, Boulder, Colorado, USA. 2011.

[24] Bährle C, Nick T, Bennati M, Jeschke G, Vogel F. High field EPR and DFT study of stable organic radicals in lignin: Influence of the extraction process, botanical origin and protonation reactions on the radical g-tensor. J. Phys. Chem. A. 2015;119:6475-82.

[25] Felby C, Nielsen BR, Olesen PO, Skibsted LH. Identification and quantification of radical reaction intermediates by electron spin resonance spectrometry of laccase-catalyzed oxidation of wood fibers from beech (Fagus sylvatica). Appl. Microbiol. Biotechnol. 1997;48:459-64.

[26] Nilges M, Swartz HM, Riley PA. Identification by electron spin resonance of free radicals formed during the oxidation of 4-hydroxyanisole catalyzed by tyrosinase. J. Biol. Chem. 1984;259:2446-51.

[27] Suurnäkki A, Oksanen T, Orlandi M, Zoia L, Canevali C, Viikari L. Factors affecting the activation of pulps with laccase. Enzyme Microb. Technol. 2010;46:153-8. 
[28] Czechowski F, Golonka I, Jezierski A. Organic matter transformation in the environment investigated by quantitative electron paramagnetic resonance (EPR) spectroscopy: studies on lignins. Spectrochim. Acta A. 2004;60:1387-94.

[29] Munk L, Punt A, Kabel M, Meyer AS. Laccase catalyzed grafting of- $\mathrm{N}-\mathrm{OH}$ type mediators to lignin via radical-radical coupling. RSC Adv. 2017;7:3358-68.

[30] Baiocco P, Barreca AM, Fabbrini M, Galli C, Gentili P. Promoting laccase activity towards non-phenolic substrates: a mechanistic investigation with some laccase-mediator systems. Org. Biomol. Chem. 2003;1:191-7.

[31] Barsberg S, Thygesen LG. Spectroscopic properties of oxidation species generated in the lignin of wood fibers by a laccase catalyzed treatment: electronic hole state migration and stabilization in the lignin matrix. BBA Gen. Subjects 1999;1472:625-42.

[32] Steelink C. Stable phenoxy radicals derived from phenols related to lignin. J. Am. Chem. Soc. 1965;87:2056-7.

[33] Ragauskas AJ, Beckham GT, Biddy MJ, Chandra R, Chen F, Davis MF, Davison BH, Dixon RA, Gilna P, Keller M, Langang P, Naskar AK, Saddler JN, Tschaplinski TJ, Tuskan GA, Wyman CE. Lignin valorization: Improving lignin processing in the biorefinery. Science 2014;344:709-19. 


\section{Figure legends}

Figure 1. Overlay of EPR spectra showing signal response over time of suspensions ( $10 \mathrm{wt} \%$ solid) measured at varying time points during laccase treatment with Tv and Mt laccase (2U/g DM biomass).

Figure 2. Left column a): Overlay of EPR spectra from each suspension (red) and supernatant (green). All EPR spectra measurements shown are after 30 min of laccase treatment. Right column (b-d): Concentration of radicals in b) BOL c) SOL and d) WSL as a function of time during laccase treatment of suspensions, Mt lac $(\diamond)$, Tv lac $(\boldsymbol{\Delta})$ and corresponding supernatants $\operatorname{Mt~} \operatorname{lac}(\diamond)$, Tv lac $(\Delta)$. Laccase dose was $2 \mathrm{U} / \mathrm{g}$ solid.

Figure 3. Kinetics of radical formation during laccase action on lignin with: Tv lac (a-c) and Mt lac (d-f) of $\operatorname{BOL}(a, d)$ SOL (b, e) and WSL (c, f). Laccase was administrated in three doses $2 \mathrm{U} / \mathrm{g}$ solid ( $(\bullet), 1 \mathrm{U} / \mathrm{g}$ solid ( ), and $0.5 \mathrm{U} / \mathrm{g}$ solid $(\mathbf{\Lambda})$.

Figure 4. Initial rates of laccase catalyzed formation of radicals as a function of laccase dose a) Tv lac, b) Mt lac on WSL $(\bullet)$, SOL $(\bullet), \operatorname{BOL}(\mathbf{\Delta})$.

Figure 5. The contour plot and the response surface plot of the radical formation rate on $\mathrm{BOL}$ catalysed by Tv laccase $(2 \mathrm{U} / \mathrm{g})$ as a function of $\mathrm{pH}$ and temperature $\left({ }^{\circ} \mathrm{C}\right)$.

Figure 6. The contour plot and the response surface plot of the radical formation rate on $\mathrm{BOL}$ catalysed by $\mathrm{Mt}$ laccase $(2 \mathrm{U} / \mathrm{g})$ as a function of $\mathrm{pH}$ and temperature $\left({ }^{\circ} \mathrm{C}\right)$. 

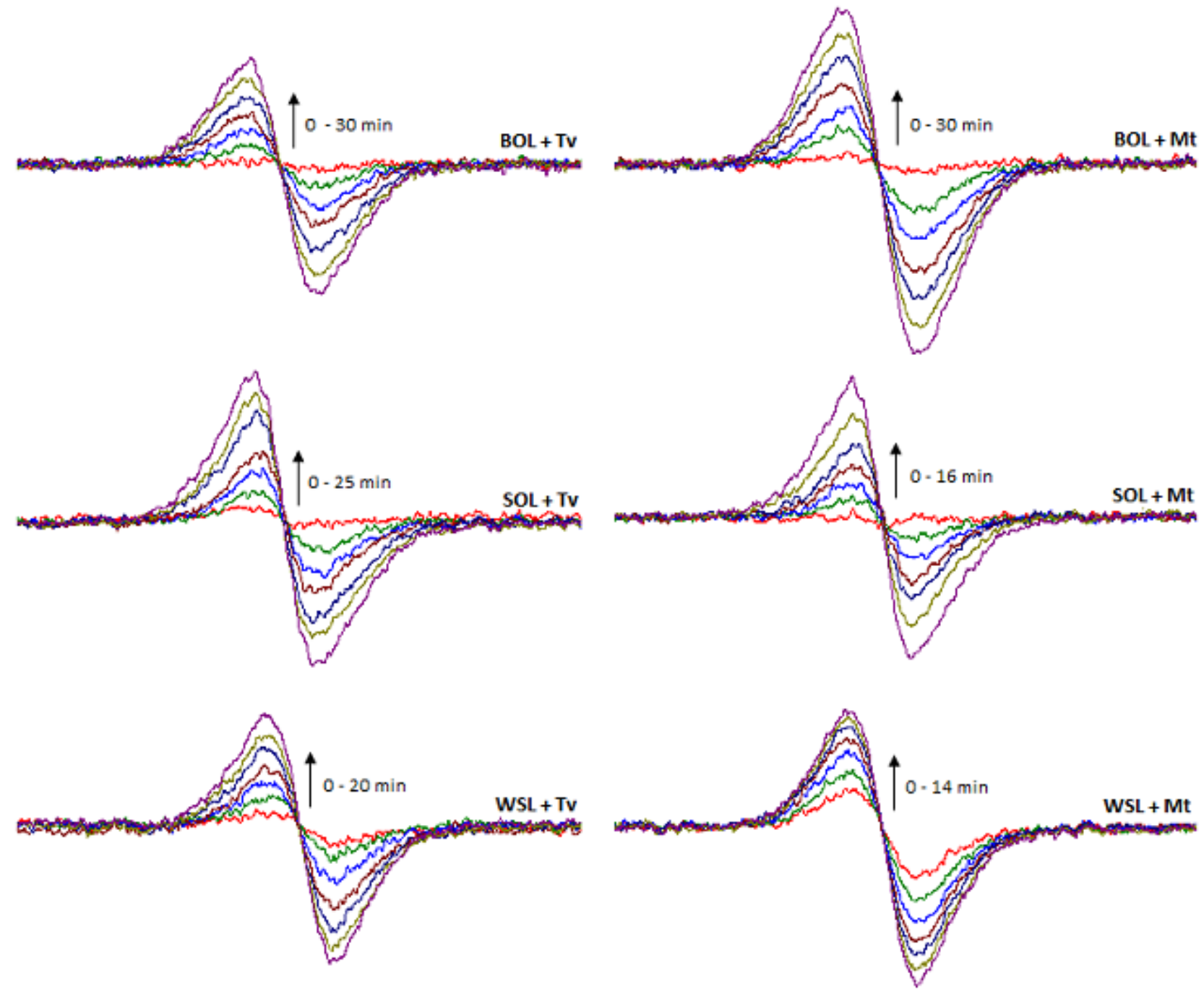

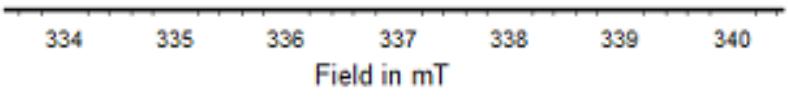

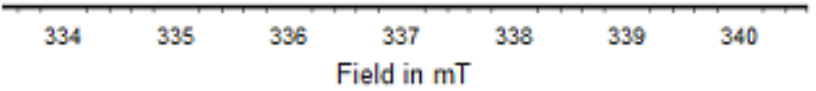

Figure 1. 

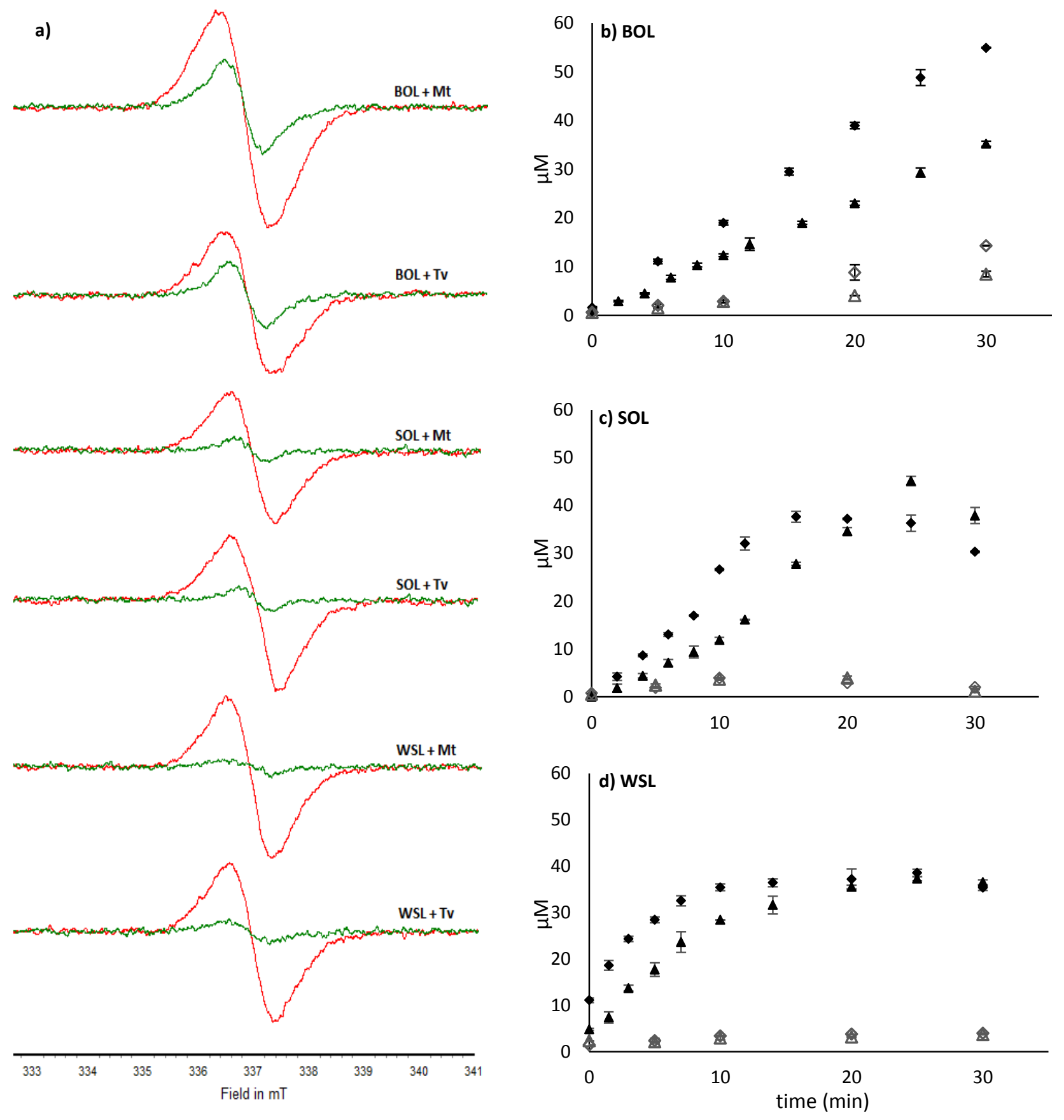

Figure 2. 

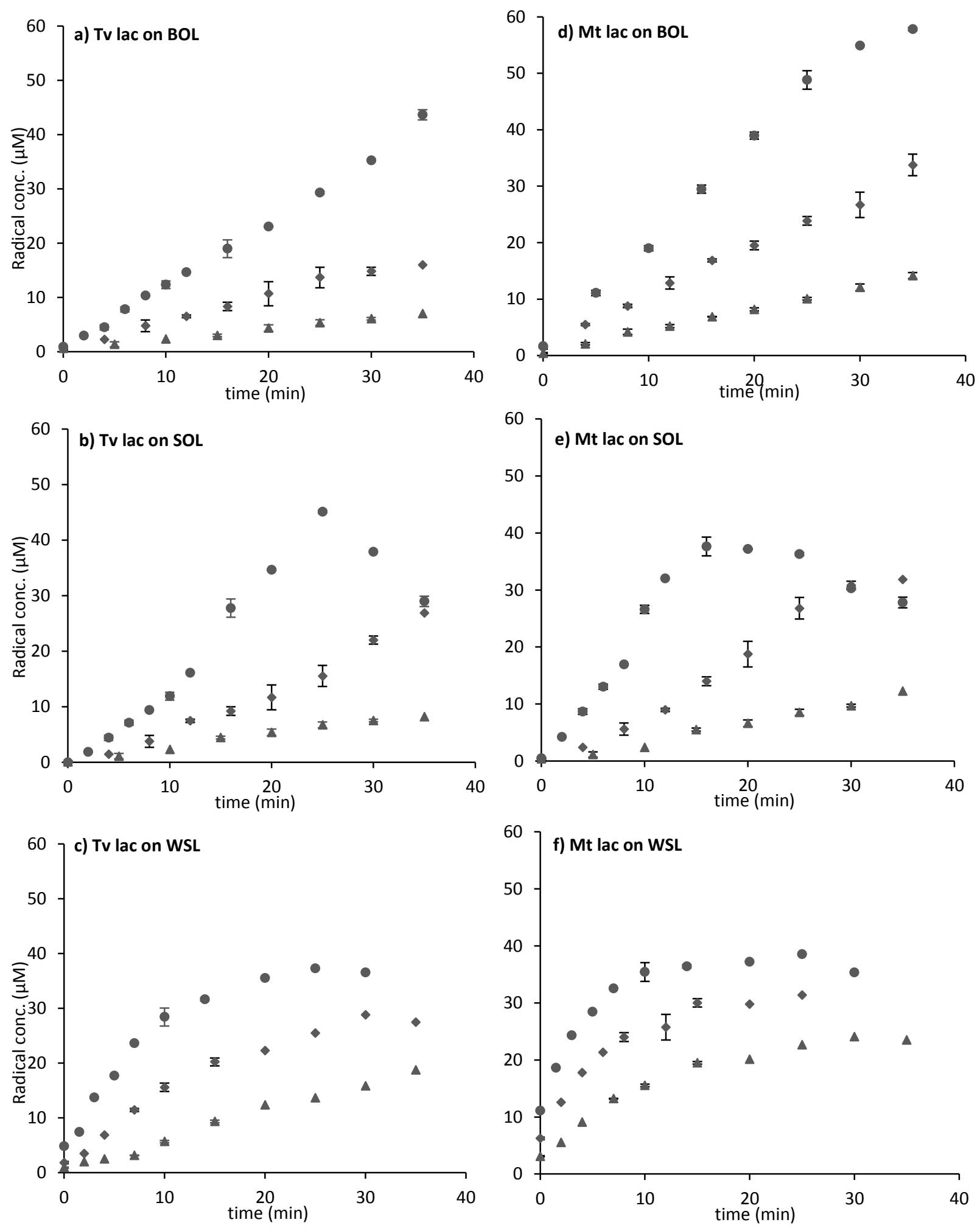

Figure 3. 

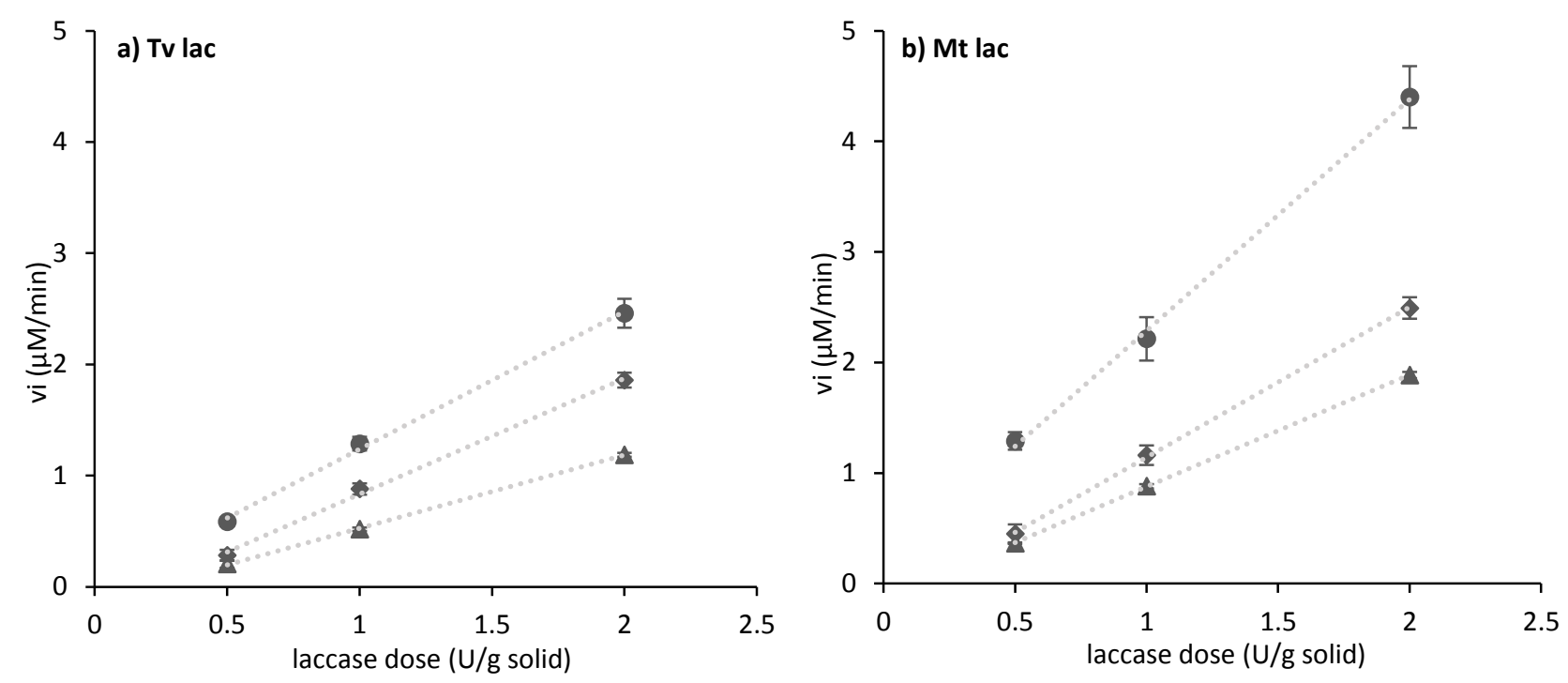

Figure 4. 

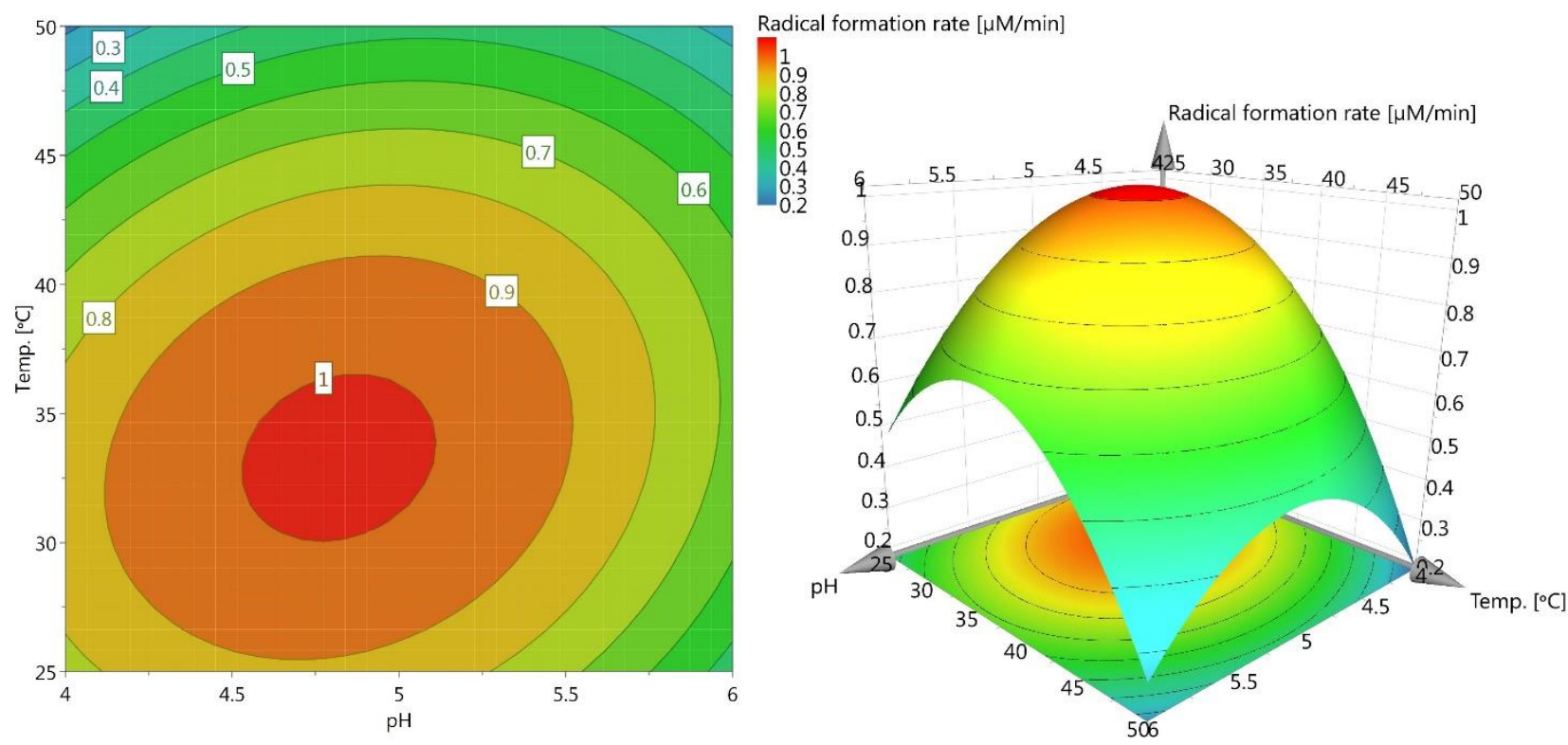

Figure 5 

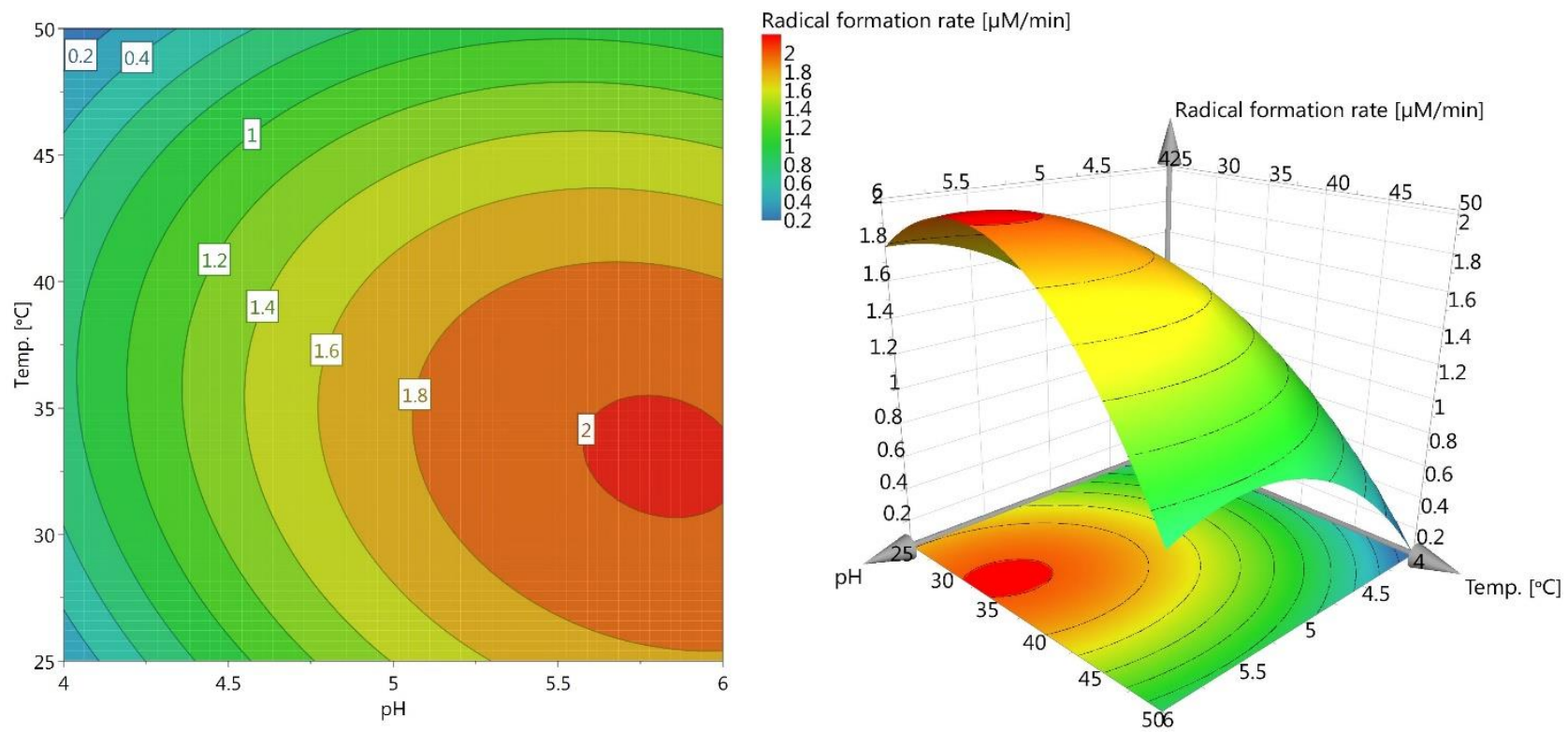

Figure 6 
Table 1. EPR g-values of the lignin suspensions and supernatants Standard deviations varied from $10^{-5}-10^{-4}$

\begin{tabular}{lllllll}
\hline & \multicolumn{3}{c}{ Suspension } & \multicolumn{4}{c}{ Supernatant } \\
& BOL & SOL & WSL & BOL & SOL & WSL \\
\hline Tv lac & 2.0050 & 2.0046 & 2.0047 & 2.0050 & 2.0049 & 2.0048 \\
Mt lac & 2.0049 & 2.0046 & 2.0047 & 2.0051 & 2.0050 & 2.0048 \\
\hline
\end{tabular}


Table 2. Slopes calculated by linear regression of linearity between the initial rates $\left(v_{i}\right)$ of radical formation in BOL, SOL and WSL versus doses of TV and Mt laccase, for amount of the lignin substrate (Solid DM) and after adjustment in response to Klason lignin. All slopes had a correlation coefficient corresponding to a value of $R^{2} \geq 0.997$ and standard deviations were in the range of 0.01-0.08. The significant differences $(p \leq 0.05)$ between the slopes column-wise are shown as superscripted letters ( $a-c)$ and significant difference $(p \leq 0.05)$ between the slopes row-wise are shown as superscripted letters $(x-y)$.

\begin{tabular}{lll|ll}
\hline & \multicolumn{3}{c}{ Dose based on Solid DM } & \multicolumn{2}{l}{ Dose accounted for Klason lignin } \\
& $v_{\mathrm{i}} /$ Tv dose & $\mathrm{v}_{\mathrm{i}} /$ Mt dose & $\mathrm{v}_{\mathrm{i}} /$ Tv dose & $\mathrm{v}_{\mathrm{i}} /$ Mt dose \\
\hline BOL & $0.66^{\mathrm{a}, \mathrm{x}}$ & $1.01^{\mathrm{a}, \mathrm{y}}$ & $0.57^{\mathrm{a}, \mathrm{x}}$ & $0.88^{\mathrm{a}, \mathrm{y}}$ \\
SOL & $1.03^{\mathrm{b}, \mathrm{x}}$ & $1.36^{\mathrm{b}, \mathrm{y}}$ & $0.98^{\mathrm{b}, \mathrm{x}}$ & $1.28^{\mathrm{b}, \mathrm{y}}$ \\
WSL & $1.24^{\mathrm{c}, \mathrm{x}}$ & $2.09^{\mathrm{c}, \mathrm{y}}$ & $0.54^{\mathrm{a}, \mathrm{x}}$ & $0.91^{\mathrm{a}, \mathrm{y}}$ \\
\hline
\end{tabular}

